\title{
Propagation Processes of the Madden-Julian Oscillation Synchronized with an Extratropical Cyclone Observed in Late October during CINDY2011
}

\author{
Qoosaku Moteki \\ Department of Coupled Ocean Atmosphere Land Processes (DCOP), \\ Japan Agency for Marine-Earth Science and Technology, Yokosuka, Japan
}

\begin{abstract}
The eastward propagation processes of the Madden-Julian oscillation (MJO) was examined from a case study of the first MJO generated in late October during CINDY2011. The eastward propagation of the MJO was found to be synchronized with an extratropical cyclone in the Southern Hemisphere. The synchronized propagation of the MJO and the extratrpical cyclone was associated with the ridge and trough pair meridionally extending between $30^{\circ} \mathrm{S} \sim 15^{\circ} \mathrm{N}$. The convection center of the MJO shifted eastward as a result of the westerly winds in the tropics, expanding eastward by the zonal pressure gradient force between the ridge and trough.

(Citation: Moteki, Q., 2016: Propagation processes of the Madden-Julian oscillation synchronized with an extratropical cyclone observed in late October during CINDY2011. SOLA, 12, 60-64, doi:10.2151/sola.2016-013.)
\end{abstract}

\section{Introduction}

The Madden-Julian oscillation (MJO; Madden and Julian 1972) is a large-scale convection slowly propagating eastward at approximately $5 \mathrm{~m} \mathrm{~s}^{-1}$ over the equator. The mechanism of the eastward propagation of the MJO is one of the biggest questions in meteorology at present. Previously proposed mechanisms of the eastward propagation of the MJO can be divided into two streams: the internal (tropical) forcing based on equatorial dynamics and the external (extratropical) forcing associated with the interactions between the tropics and mid-latitudes.

The tropical internal forcing, a frictional wave-CISK (conditional instability of the second kind) proposed by Wang and Rui (1990), is one of the most popular theories to explain the eastward propagation of the MJO. Thus, the theory assumes that the frictional surface moisture convergence is expanded due to the interaction between equatorial Rossby and Kelvin waves, which are excited by convection. The frictional wave-CISK theory has been improved and validated by numerous studies using numerical simulations and statistical analyses (e.g., Maloney and Hartmann 1998; Matthews 2000; Seo and Kim 2003).

With regard to extratropical external forcing, many studies have suggested the influence of baroclinic waves that propagate equatorward (Hsu et al. 1990; Lin et al. 2000; Matthews and Kiladis 1999). For example, the analyses by Slingo (1998) have suggested that accurate numerical simulations of the MJO may require those interactions between the tropics and mid-latitudes. However, statistical signals of the interactions between the tropics and mid-latitudes are not clear, and the consistency between internal and external forcing theories has not yet been well understood. In addition, we should consider not only the proposed internal and external forces but also their combination because the MJO events have distinct features and develop in different environmental conditions (e.g., primary and successive events, Matthews 2008; equatorially symmetric and asymmetric events, Tung et al. 2014).

Moteki (2015) has noted that the three MJO events observed

Corresponding author: Qoosaku Moteki, Department of Coupled Ocean Atmosphere Land Processes, Japan Agency for Marine-Earth Science and Technology (DCOP, JAMSTEC), 2-15 Natsushima-cho, Yokosuka, Kanagawa, 237-0061, Japan. E-mail: moteki@jamstec.go.jp. (C2016, the Meteorological Society of Japan. during the cooperative Indian Ocean experiment on intraseasonal variability in the year 2011 (CINDY2011, Yoneyama et al. 2013; Zhang 2013) were synchronized with strong extratropical cyclones traveling over the Indian Ocean in the Southern Hemisphere. In particular, the mature phase of the primary MJO observed in late October 2011 was completely synchronized with the passage of a very strong extratropical cyclone over the Indian Ocean. The purpose of this study is to investigate the extratropical cyclone in the Southern Hemisphere synchronized with the MJO.

\section{Data}

The Japanese 55-year reanalysis from 1958-2012 (JRA-55, Ebita et al. 2011; Kobayashi et al. 2015) was used to investigate the large-scale environment. The dataset has a $1.25^{\circ}$ horizontal resolution, 38 levels (the surface and $1-1000 \mathrm{hPa}$ ), and 6-h intervals. A majority of the intensive observations from CINDY were transmitted to operational centers to be assimilated in the reanalysis. Moteki (2015) has confirmed that the qualitative patterns of averaged large-scale fields with the JRA-55 are largely consistent with other objective analysis datasets (e.g., ERA-Interim, Dee et al. 2011). The daily estimates of outgoing long-wave radiation (OLR) with a $2.5^{\circ}$ resolution from polar-orbiting satellites (Gruber and Krueger 1984) were provided by the National Oceanic and Atmospheric Administration (NOAA).

\section{Synchronized eastward propagation of an extra- tropical cyclone and MJO}

Moteki (2015) has revealed that the October-MJO in 2011 developed as the pressure field in the Southern Hemisphere drastically changed and was associated with the decay of the Mascarene High and the passage of a strong extratropical cyclone. The features of the pressure field over the Indian Ocean were consistent with previous studies that addressed the influence of mid-latitudes in the Southern Hemisphere on the MJO development (e.g., Adames et al. 2014; Kerns and Chen 2014; Ray and Zhang 2010). Here, we focus on the synchronized eastward propagation of the extratropical cyclone and the MJO from the Indian Ocean to the Maritime Continent.

Figure 1 shows the longitude-time cross sections of normalized geopotential height anomaly (NZA), westerly wind speed, and OLR. The NZA is normalized for the meridional difference in the amplitude of the geopotential height variation according to the following calculation:

$$
\mathrm{NZA}=\frac{Z-\operatorname{mean}(Z)}{\operatorname{std}(Z)}
$$

where mean $(Z)$ and $\operatorname{std}(Z)$ are the zonal mean and standard deviation of geopotenital height $Z$ between $40^{\circ} \mathrm{E}-140^{\circ} \mathrm{E}$, respectively, for each latitude. The large-scale low-height anomaly over the equator shown in Fig. $1 \mathrm{~b}$ is shifted to the east in advance of the eastward-propagating MJO convection (indicated by OLR) at a speed of approximately $6 \mathrm{~m} \mathrm{~s}^{-1}$ with westerly winds. The features of the NZA, OLR, and westerly winds are consistent with the typical MJO depicted by the schematic illustration of Madden and Julian (1972) as described in Moteki (2015). Between $10^{\circ} \mathrm{S}-30^{\circ} \mathrm{S}$ (Fig. 1c), the eastward-propagation of the low-height anomaly 
associated with the extratropical cyclone (along the red line indicating the phase speed of $6 \mathrm{~m} \mathrm{~s}^{-1}$ ) is synchronized with that of the MJO. In contrast, between $10^{\circ} \mathrm{N}-30^{\circ} \mathrm{N}$ (Fig. 1a), the low-height anomalies essentially propagate westward and there are almost no features corresponding to the eastward propagation of the MJO. Such an equatorially antisymmetric feature of the NZA suggests that the eastward propagation of the MJO could be combined with the extratropical cyclone in the Southern Hemisphere. Figure 2 shows the daily averaged NZA, westerly winds and SLP. Until 26 October, immediately after the MJO onset date of 21 October, the standing Mascarene High (surrounded by the representative SLP threshold of $1010 \mathrm{hPa}$, shown by the bold blue contour in Fig. 2a) was significant to the south of $15^{\circ} \mathrm{S}$ (the maximum SLP of 1022
$\mathrm{hPa}$ was at $\left.38^{\circ} \mathrm{S}, 92^{\circ} \mathrm{E}\right)$.

After 26 October, the very strong extratropical cyclone (992 $\left.\mathrm{hPa} ; 40^{\circ} \mathrm{S}, 60^{\circ} \mathrm{E}\right)$ appears and the strong westerly winds behind the cold front (corresponding to the maxima of synoptic ascending and zonal gradients of the equivalent potential temperature shown in Supplement 1) are observed to the southeast of Madagascar Island (Fig. 2a). On 29 October, a meridionally extending trough of low-NZA forms over the western Indian Ocean as a result of the approach of the extratropical cyclone to the low-NZA area of the MJO (Fig. 2b). In addition, the westerlies behind the cold front which has the zonal gradients of the equivalent potential temperature $(0.5-1.2 \mathrm{~K} / 1000 \mathrm{~km}$, see Supplement 1$)$ intrude equatorward to the north of $15^{\circ} \mathrm{S}$, and a cross-equatorial ridge of high-NZA
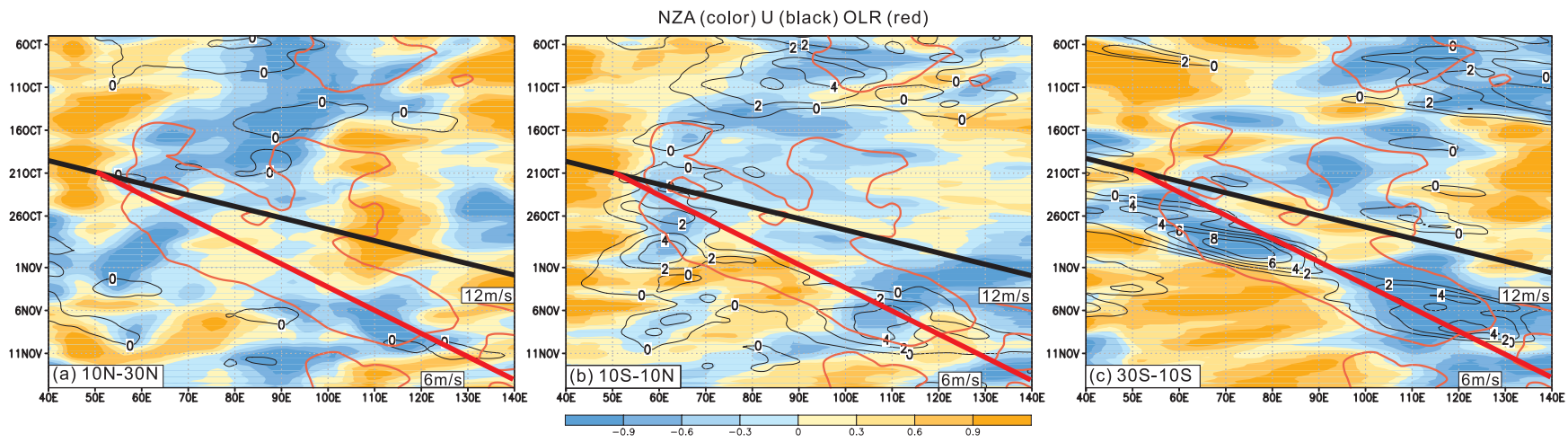

Fig. 1. Time-longitude sections of the 1-day running mean NZA (color) and westerly wind speed (black contours for every $2 \mathrm{~m} \mathrm{~s}^{-1}$ ) averaged between (a) $10^{\circ} \mathrm{N}$ and $30^{\circ} \mathrm{N}$, (b) $10^{\circ} \mathrm{S}$ and $10^{\circ} \mathrm{N}$, and (c) $30^{\circ} \mathrm{S}$ and $10^{\circ} \mathrm{S}$. The red contours of OLR $\left(210 \mathrm{~W} \mathrm{~m}^{-2}\right.$ ) averaged between $10^{\circ} \mathrm{S}$ and $10^{\circ} \mathrm{N}$ are shown in all panels. The black and red lines represent the phase speeds of 12 and $6 \mathrm{~m} \mathrm{~s}^{-1}$, respectively.

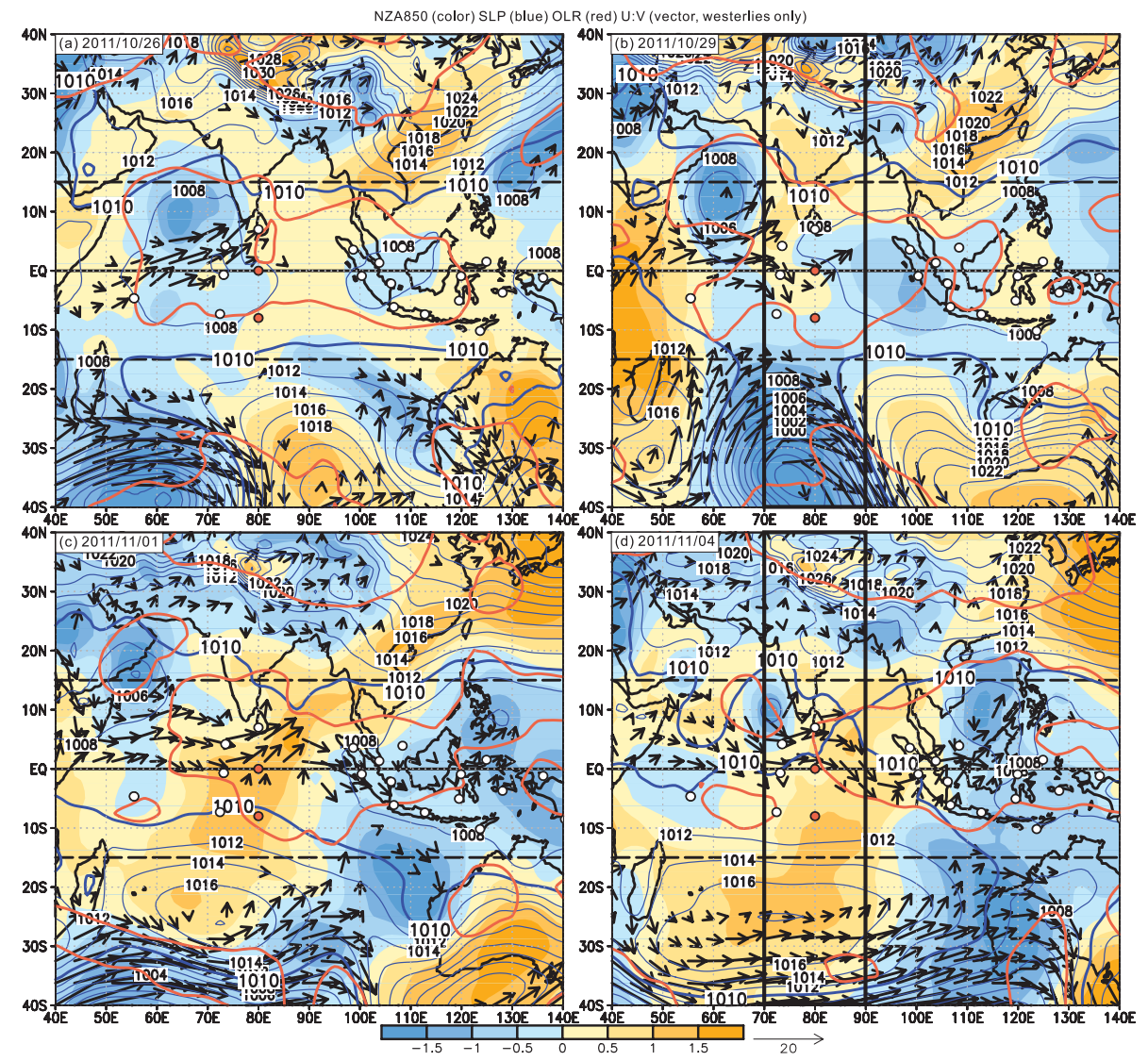

Fig. 2. Horizontal distributions of the daily averages of NZA at $850 \mathrm{hPa}$ (color) and SLP (blue contours for every $2 \mathrm{hPa}$ and bold blue contours of 1010 hPa) on (a) 26 October, (b) 29 October, (c) 1 November, and (d) 4 November in 2011. The red contours of OLR (230 W m $\left.{ }^{-2}\right)$ are shown in all panels. The vectors show the westerly winds $\left(\mathrm{m} \mathrm{s}^{-1}\right)$ at $850 \mathrm{hPa}$. The intensive upper air-sounding sites and research vessels from the CINDY campaign are shown by white and red circles, respectively. The rectangle in (b) and (d) indicates the averaged area between $70^{\circ} \mathrm{E}$ and $90^{\circ} \mathrm{E}$ for Fig. 3 . 
appears along the eastern coast of Africa.

On 1 November, the extratropical cyclone decays after landing over the western coast of Australia, and a traveling anticyclone is dominant over the southern Indian Ocean (Fig. 2c). As a result of the migration of the extratropical cyclone and anticyclone, the ridge and trough pair that extends cross-equatorially at $850 \mathrm{hPa}$ is shifted to the eastern Indian Ocean. The fact that the region of westerly winds at $850 \mathrm{hPa}$ over the equator expands eastward to the Maritime Continent is consistent with the eastward pressure gradient force from the ridge to the trough. On 4 November, the anticyclone over the southern Indian Ocean is strengthened, and the high NZA region greater than $1010 \mathrm{hPa}$ expands to the tropics to the north of $15^{\circ} \mathrm{S}$ (Fig. 2d). The ridge of positive NZA at $850 \mathrm{hPa}$ expands over the entire Indian Ocean, and the trough of negative NZA extends from the western coastal region of Australia to the Maritime Continent. Under the situation in which the eastward pressure gradient force pushes toward the Maritime Continent from the Indian Ocean, the region of westerly winds advances to $130^{\circ} \mathrm{E}$ across the equator. The eastward shift of the center of the MJO convection from the Indian Ocean to the Maritime Continent is consistent with the fact that the convection over the Indian Ocean is suppressed under the positive NZA, and the region of westerly winds expands eastward along the zonal pressure gradient force between the trough and ridge.

Figure 3 shows the vertical cross sections of NZA averaged between $70^{\circ} \mathrm{E}-90^{\circ} \mathrm{E}$ to show the meridional vertical structure of trough and ridge. The meridionally-extending trough structure

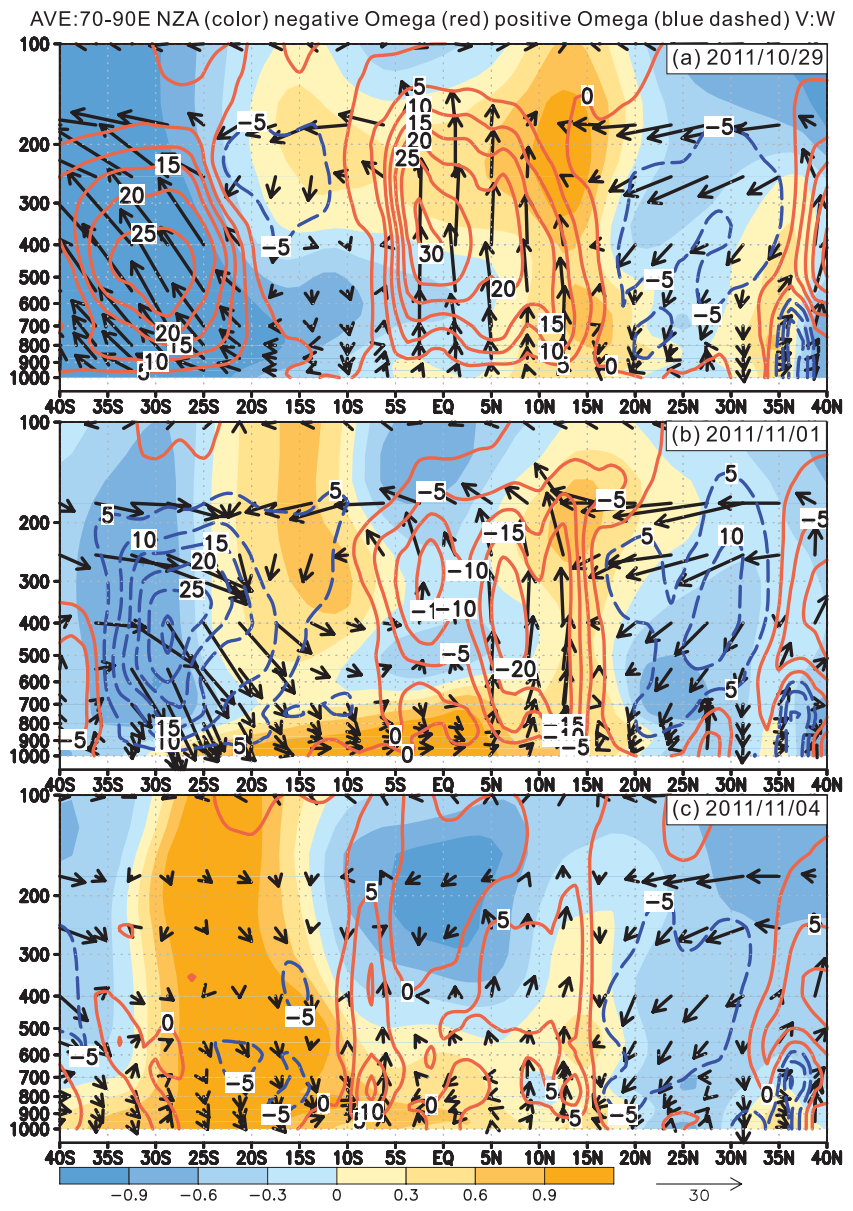

Fig. 3. Vertical distributions of the daily averaged NZA (color) and negative vertical pressure velocity (red contours of ascending and blue dashed contours of descending for $5 \times 10^{-2} \mathrm{~Pa} \mathrm{~s}^{-1}$ ) averaged between $70^{\circ} \mathrm{E}$ and $90^{\circ} \mathrm{E}$ on (a) 29 October, (b) 1 November, and (c) 4 November in 2011. The vectors of the mass flux $(\rho v)$ of the meridional wind speed and vertical pressure velocity are shown. Vertical pressure velocities have been scaled by a factor of 100 . is seen below $500 \mathrm{hPa}$ in the tropics on 29 October (Fig. 3a) and the ridge appears below $500 \mathrm{hPa}$ on 1-4 November (Fig. 3b, c). Between $15^{\circ} \mathrm{S}-5^{\circ} \mathrm{N}$, the ridge and trough of NZA have a $1 \mathrm{st}$ baroclinic mode with the opposite signs below and above 500 $\mathrm{hPa}$ as the internal mode of the tropics. However, such baroclinic structure of NZA gradually changes to the barotropic structure in seamless manners in the Southern Hemisphere but is separated to the north of $15^{\circ} \mathrm{N}$ in the Northern Hemisphere.

The synchronized eastward propagation between the tropics and extratropics in the Southern Hemisphere is observed in the ascending motion at $850 \mathrm{hPa}$ (Fig. 4). On 29 October, the colder air (indicated by the blue contours) behind the cold front (see Supplement 2) intrudes into the tropics to the north of $15^{\circ} \mathrm{S}$, and the ascending areas of both the MJO and extratropical cyclone are combined (Fig. 4a). On 4 November, the ascending areas meridionally extending from the Maritime Continent to Australia form ahead of the westerly winds and the area of the northward cold air advection from the traveling anticyclone is shifted to the eastern Indian Ocean (Fig. 4b). The positive NZA of the traveling anticyclone appears below $500 \mathrm{hPa}$ in the tropics (Figs. 3b, c) and the ascending motion of the MJO convection is significantly weakened in comparison of that on 29 October. Such drastic change of NZA field in the Southern Hemisphere consequently induced the eastward propagation of the MJO. The eastward propagation of the extratropical cyclone and accompanying anticyclone is found to be a triggering factor of that of the MJO convection.

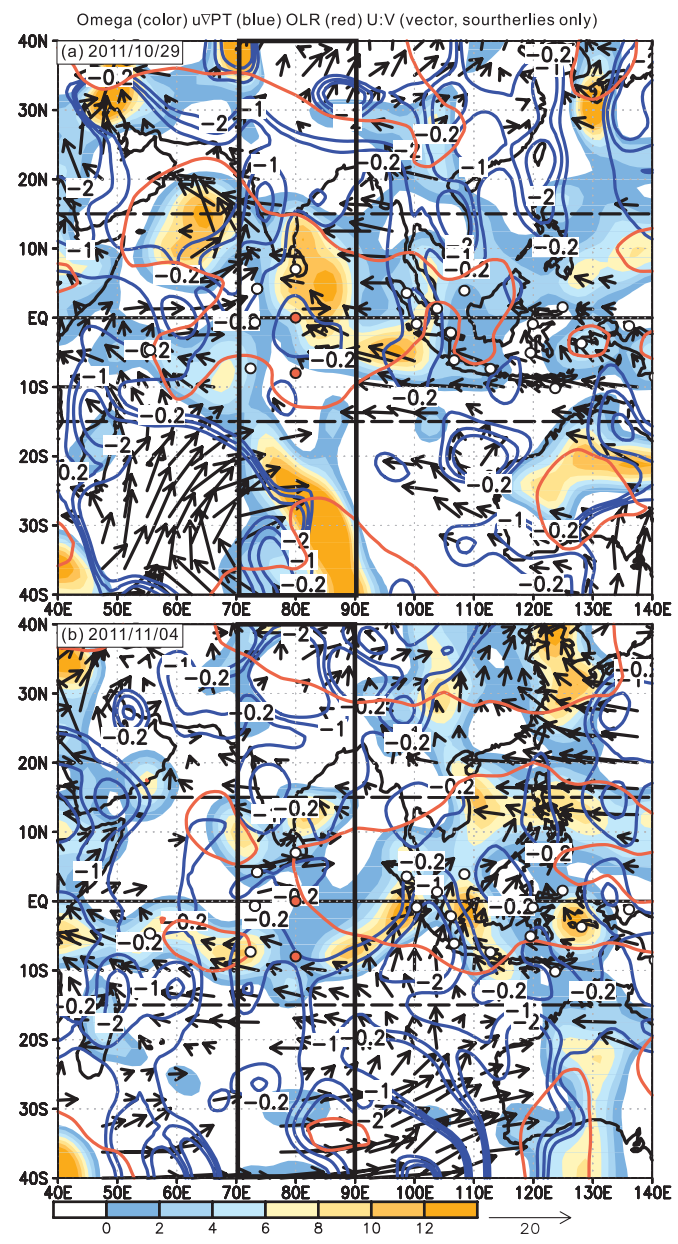

Fig. 4. Horizontal distributions of the daily averaged negative vertical pressure velocity (ascending flow indicated by color, $1 \times 10^{-2} \mathrm{~Pa} \mathrm{~s}^{-1}$ ), negative temperature advection (blue contours for $-0.2,-1$, and $-2 \times$ $10^{-2} \mathrm{~K} \mathrm{~m} \mathrm{~s}^{-1}$ ), and the vectors of the southerly winds at $850 \mathrm{hPa}$ on (a) 29 October and (b) 4 November in 2011. The rectangle indicates the averaged area between $70^{\circ} \mathrm{E}$ and $90^{\circ} \mathrm{E}$ for Fig. 3. The red contours of OLR (230 $\mathrm{W} \mathrm{m}^{-2}$ ) are shown 


\section{Conclusion and discussion}

The eastward propagation processes of the MJO synchronized with an extratropical cyclone over the southern Indian Ocean was exmamined from a case of the first MJO generated in late October during CINDY2011. The proposed scenario is that the eastward propagation of the MJO is triggered by that of an extratropical cyclone in the summer (southern) hemisphere. The ridge and trough pair meridionally extending between $30^{\circ} \mathrm{S}$ and $15^{\circ} \mathrm{N}$ accompanied by the extratropical cyclone was found to be synchronized with the eastward propagating MJO convection. Figure 5 shows the schematic illustrations summarizing the proposed scenario based on the features in Figs. 2, 3, 4. The features of simplified background SLP pattern (light blue: < $1010 \mathrm{hPa}$; pink: > 1010 $\mathrm{hPa}$, based on Fig. 2), the trough and ridge at $850 \mathrm{hPa}$ (indicated by a dashed line and solid line drawn subjectively based on the NZA of Fig. 2) and the symbol of the cold front representing the head of westerly winds with the zonal gradients of the equivalent potential temperature at $850 \mathrm{hPa}$ (Supplement 1) are schematically depicted.

As the MJO propagated from the Indian Ocean to the Maritime Continent, the pressure field in the summer (southern) hemisphere was drastically changed in association with the traveling extratropcial cyclone and anticyclone, whereas a high-pressure field greater than $1010 \mathrm{hPa}$ continued to be dominant in the winter (northern) hemisphere. Thus, the meridionally extending trough between $30^{\circ} \mathrm{S}$ and $15^{\circ} \mathrm{N}$ formed over the western Indian Ocean as a result of the decay of the Mascarene High and the passage of the strong extratropical cyclone (Figs. 5a, b). Furthermore, the northward cold air advection with the positive geopotential height anomalies behind the cold front intruded into the tropics, and the ascending areas of the MJO and extratropical cyclone combined at 850-hPa (Fig. 5b).
The traveling anticyclone and ridge at $850 \mathrm{hPa}$ behind the cold front suppressed the convection over the western and central Indian Ocean, and the center of the MJO convection shifted eastward. The eastward expansion of the westerly wind area is consistent with the direction of the height gradient force between the ridge and trough and corresponds to the eastward propagation speed of the MJO. Thus, the eastward propagation of the MJO could be triggered by the ridge and trough pair meridionally extending between $30^{\circ} \mathrm{S}$ and $15^{\circ} \mathrm{N}$.

This proposed scenario is consistent with the notion that environmental conditions in the subtropics and mid-latitudes influence the initiation and development of the MJOs (Adames et al. 2014; Frederiksen and Lin 2013; Fukutomi and Yasunari 2014; Ray and Zhang 2010). For example, Ray and Zhang (2010) have found that substantial wave activity propagated northward toward the tropics from the southern Indian Ocean, and the latitudinal transport of the westerly momentum was crucial for the MJO development. The northward progress of the cold front shown in Figs. $4 a, b$ is one of the specific processes that induce the latitudinal transport of the westerly momentum. Fukutomi and Yasunari (2014) have statistically revealed that the mid-latitude wave propagation toward the subtropics induces the growth of the trough and ridge, which extends across the tropics and subtropics over the Indian Ocean. Their results are consistent with the fact that the trough and ridge pair extending across the tropics and subtropics forms in association with the eastward propagation of the extratropical cyclone and accompanying anticyclone.

However, one of the questions raised by this scenario is the reason why the prediction of the eastward propagation of the MJO is difficult in spite of a relatively high predictability of the extratropical cyclone. One of the candidate reasons is the fact that accurately representing the ascending/convergence combined between the tropics and subtropics is difficult in typical global forecast systems because their cumulus parameterization is optimized

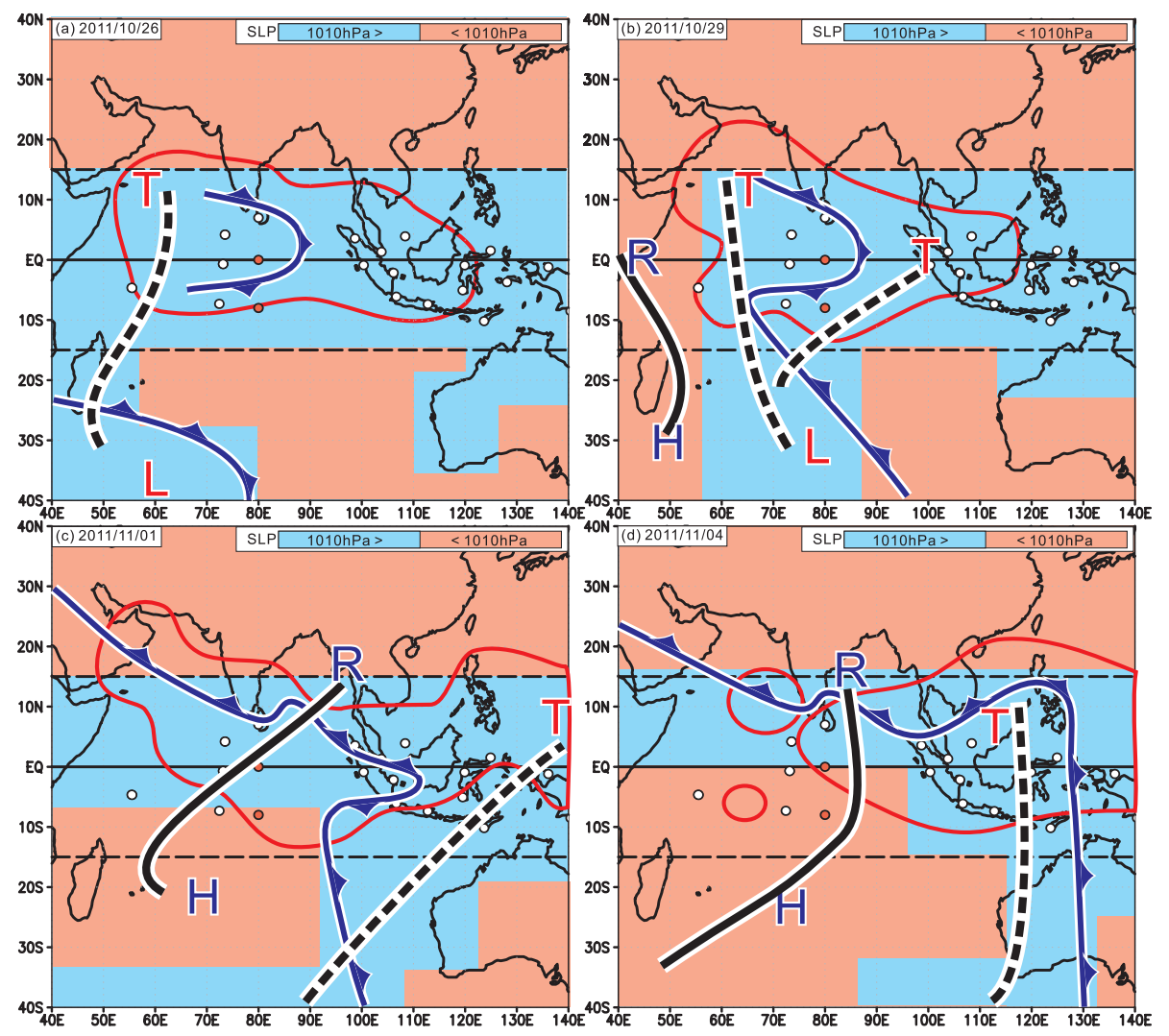

Fig. 5. Schematic illustrations of the SLP, ridge/trough at $850 \mathrm{hPa}$ surrounding the MJO on (a) 26 October, (b) 29 October, (c) 1 November, and (d) 4 November in 2011. The symbol of the cold front means the synoptic ascending area ahead the westerly winds with the zonal gradients of the equivalent potential temperature at $850 \mathrm{hPa}$. The sold and dashed lines labeled by "R" and "T" subjectively indicate the ridge and trough at $850 \mathrm{hPa}$, respectively. The red contours of OLR $\left(230 \mathrm{~W} \mathrm{~m}^{-2}\right)$ are shown in all panels. 
for mid-latitudes (e.g., Chikamoto et al. 2007). Slingo (1998) has also suggested that accurate numerical simulations of the MJO could require simulations of the interactions between the tropics and mid-latitudes. Such a suggestion from previous studies is consistent with the fact that the eastward propagation of the MJO is successfully reproduced by a global cloud-resolving model (Miura et al. 2007).

In future studies, detailed analyses for other MJO events to which the proposed scenario can be applied will be desirable. For example, the MJO events in November 2011 and March 2012, during CINDY, which were associated with the synchronized propagation of an extratropical cyclone, as well as the present case (Moteki 2015), should be studied to validate the scenario. Also, quantitative analyses on the latitudinal momentum transport and the zonal pressure gradient force to increase the westerly winds should be addressed in the future. Furthermore, a statistical comparison of the geopotential anomaly patterns between various types of MJOs (e.g., primary and successive events, Matthews 2008; equatorially symmetric and asymmetric events, Tung et al. 2014) would be important for the validation of the scenario. Actually, the relationship between the trough and frontal features has not yet been revealed robustly in the present study, various case studies with such perspective are required. A combination of tropical internal and extratropical external forcings, which are not discussed in the present study, should also be addressed.

\section{Acknowledgments}

The authors acknowledge Drs. Miki Hattori, Kunio Yoneyama, and Takuya Hasegawa of JAMSTEC for their valuable suggestions. This work is supported in part by MEXT through a grant-inaid for Scientific Research in Innovative Areas 2205 and the Japan Society for the Promotion of Science Grants-in-Aid for Scientific Research 22244057.

Edited by: T. Takemi

\section{Supplements}

Fig. S1. The same as Fig. 2 but for the zonal gradient of the equivalent potential temperature at $850 \mathrm{hPa}$ to show the cold frontal features.

Fig. S2. Longitude-height cross section of the equivalent potential temperature averaged between $15^{\circ} \mathrm{S}-5^{\circ} \mathrm{N}$ to show the cold frontal features.

\section{References}

Adames, Á. F., J. Patoux, and R. C. Foster, 2014: The contribution of extratropical waves to the MJO wind field. J. Atmos. Sci., 71, 155-176.

Chikamoto, Y., H. Mukougawa, T. Kubota, H. Sato, A. Ito, and S. Maeda, 2007: Evidence of growing bred vector associated with the tropical intraseasonal oscillation. Geophys. Res. Lett., 34, doi:10.1029/2006GL028450.

Dee, D. P., S. M. Uppala, A. J. Simmons, P. Berrisford, P. Poli, S. Kobayashi, U. Andrae, M. A. Balmaseda, G. Balsamo, P. Bauer, P. Bechtold, A. C. M. Beljaars, L. van de Berg, J. Bidlot, N. Bormann, C. Delsol, R. Dragani, M. Fuentes, A. J. Geer, L. Haimberger, S. B. Healy, H. Hersbach, E. V. Holm, L. Isaksen, P. Kallberg, M. Kohler, M. Matricardi, A. P. McNally, B. M. Monge-Sanz, J. J. Morcrette, B. K. Park, C. Peubey, P. de Rosnay, C. Tavolato, J. N. Thepaut, and F. Vitart, 2011: The ERA-Interim reanalysis: Configuration and performance of the data assimilation system. Quart. J. Roy. Meteor. Soc., 137, 553-597.

Ebita, A., S. Kobayashi, Y. Ota, M. Moriya, R. Kumabe, K. Onogi, Y. Harada, S. Yasui, K. Miyaoka, K. Takahashi, H. Kamahori, C. Kobayashi, H. Endo, M. Soma, Y. Oikawa, and T.
Ishimizu, 2011: The Japanese 55-year Reanalysis "JRA-55": An interim report. SOLA, 7, 149-152.

Frederiksen, J. S., and H. Lin, 2013: Tropical-extratropical interactions of intraseasonal oscillations. J. Atmos. Sci., 70, 31803197.

Fukutomi, Y., and T. Yasunari, 2014: Extratropical forcing of tropical wave disturbances along the Indian Ocean ITCZ. $J$. Geophys. Atoms., 119, 1154-1171.

Gruber, A., and A. F. Krueger, 1984: The status of the NOAA outgoing longwave radiation data set. Bull. Amer. Meteor. Soc., 65, 958-962.

Hsu, H. H., B. J. Hoskins, and F. F. Jin, 1990: The 1985/86 intraseasonal oscillation and the role of the extratropics. J. Atmos. Sci., 47, 823-839.

Kerns, B. W., and S. S. Chen, 2014: Equatorial dry air intrusion and related synoptic variability in MJO initiation during DYNAMO. Mon. Wea. Rev., 142, 1326-1343.

Kobayashi, S., Y. Ota, Y. Harada, A. Ebita, M. Moriya, H. Onoda, K. Onogi, H. Kamahori, C. Kobayashi, H. Endo, K. Miyaoka, and K. Takahashi, 2015: The JRA-55 reanalysis: General specifications and basic characteristics. J. Meteor. Soc. Japan, 93, 5-48.

Lin, J. W. B., J. D. Neelin, and N. Zeng, 2000: Maintenance of tropical intraseasonal variability: Impact of evaporation-wind feedback and midlatitude storms. J. Atmos. Sci., 57, 27932823.

Madden, R. A., and P. R. Julian, 1972: Description of global-scale circulation cells in the tropics with a 40-50 day period. $J$. Atmos. Sci., 29, 1109-1123.

Maloney, E. D., and D. L. Hartmann, 1998: Frictional moisture convergence in a composite life cycle of the Madden-Julian oscillation. J. Climate, 11, 2387-2403.

Matthews, A. J., 2000: Propagation mechanisms for the MaddenJulian oscillation. Quart. J. Roy. Meteor. Soc., 126, 26372651.

Matthews, A. J., 2008: Primary and successive events in the Madden-Julian Oscillation. Quart. J. Roy. Meteor. Soc., 134, 439-453.

Matthews, A. J., and G. N. Kiladis, 1999: The tropical-extratropical interaction between high-frequency transients and the Madden-Julian oscillation. Mon. Wea. Rev., 127, 661-677.

Miura, H., M. Satoh, T. Nasuno, A. T. Noda, and K. Oouchi, 2007: A Madden-Julian oscillation event realistically simulated by a global cloud-resolving model. Science, 318, 1763-1765.

Moteki, Q., 2015: Equatorially antisymmetric features in the initiation processes of the Madden-Julian oscillation observed in late October during CINDY2011. J. Meteor. Soc. Japan, doi:10.2151/jmsj.2015-040.

Ray, P., and C. D. Zhang, 2010: A case study of the mechanics of extratropical influence on the initiation of the Madden-Julian oscillation. J. Atmos. Sci., 67, 515-528.

Seo, K.-H., and K.-Y. Kim, 2003: Propagation and initiation mechanisms of the Madden-Julian oscillation. J. Geophys., 108, doi:10.1029/2002JD002876.

Slingo, J. M., 1998: Extratropical forcing of tropical convection in a northern winter simulation with the UGAMP GCM. Quart. J. Roy. Meteor. Soc., 124, 27-51.

Tung, W.-W., D. Giannakis, and A. J. Majda, 2014: Symmetric and antisymmetric convection signals in the Madden-Julian oscillation. Part I: Basic modes in infrared brightness temperature. J. Atmos. Sci., 71, 3302-3326.

Wang, B., and H. Rui, 1990: Dynamics of the Coupled Moist Kelvin-Rossby Wave on an Equatorial Beta-Plane. J. Atmos. Sci., 47, 397-413.

Yoneyama, K., C. D. Zhang, and C. N. Long, 2013: Tracking pulses of the Madden-Julian oscillation. Bull. Amer. Meteor. Soc., 94, 1871-1891.

Zhang, C. D., 2013: Madden-Julian oscillation bridging weather and climate. Bull. Amer. Meteor. Soc., 94, 1849-1870.

Manuscript received 5 October 2015, accepted 29 January 2016

SOLA: https://www.jstage.jst.go.jp/browse/solal 